\title{
Management of The Formation of The Experience of Information Activities in Students Based on Work with Educational Texts
}

\author{
Natalia Desiajeva $^{1 *}$, Larisa Assuirova ${ }^{1}$, Elvira Krivorotova $^{1}$, Ekaterina Nikolajeva $^{1}$, and \\ Lyudmila Khaymovich ${ }^{1}$
}

${ }^{1}$ GAOU VO Moscow City Pedagogical University, Moscow, Russia

\begin{abstract}
The purpose of the research is to identify the influence of an educational text on the organisation of information activities of schoolchildren. Methods: content analysis, structural and semantic analysis of educational texts and the results of their interpretation. Research results: identification of features of the educational text as an information structure (the integrity of multi-layer content, reproducibility, presence of system connections with the thematic information field), description of the information activity of a complex of educational texts united by the function of updating the value attitude to knowledge, which can be represented in three main types: impersonal, authorised and personal. Each of these types is correlated with the level of perception of information by the studentreader, which can be a. detached and impersonal, b. in conscious collaboration with the author, c. to their own cognitive experience. As a result of the research, the basic information-significant structural components of educational texts are also identified: the title and the beginning correlated with the key meaning of the text, the means of axiological field and dialogisation.
\end{abstract}

\section{Introduction}

The formation of information competence of a schoolchild is one of the most important tasks solved by the modern education system. Its significance is determined by the fact that the ability to plan the receipt of information, select information sources, analyze them and structure the information received following the task depends on the achievement of both social and personal goals of a person throughout life. In the modern school, the solution to this problem is dispersed within various educational areas. This often leads to paradoxical situations: a graduate with sufficiently developed skills in the field of digital information technologies is not ready to accept information from an artistic, metaphorical, text. At the same time, a schoolchild who easily perceives the text in its fullness of obvious and subtext content is not able to structurally formalise their interpretation of the speech work at the modern level. In this regard, it is obvious that there is a need to find a key object of educational activity, work with which would contribute to the integration of all the

\footnotetext{
*Corresponding author: 481795@mail.ru
} 
information skills that a child receives at school. Such an object is seen as an educational text (a speech work reflecting the educational paradigm of scientific knowledge, intended for the integrated transfer of ontological and axiological information from a particular field of science) since it has a set of features of an integral information structure:

- integrity of multi-layer content,

- reproducibility,

- system links to the thematic information field.

It is also important that educational texts are presented in various educational fields - this makes it easier to transfer the skills of working with educational text obtained in a particular educational field to any other area.

Despite the rather close attention to academic texts in science [1-8] in educational practice, they were not considered as a means of managing the formation of a student's information competence. Thus, the prerequisites for setting the problem disclosed in the article are obvious: the educational polyfunctionality of the educational text, its information and activity potential. The problem itself is formulated as follows: what structural features of educational texts are associated with their ability to manage the development of the student's information competence, in particular, to ensure the formation of experience in predicting results, planning, organising, coordinating, monitoring the progress and result of information activities.

The purpose of the research is to identify the influence of the educational text on the organisation of information activities of schoolchildren. Objectives of the study: a. feature extraction of the training text information structure, b. justification of information activity of a complex of educational texts as the most frequent textual information units in the training processes, c. identifying core information and important structural components of educational texts.

\section{Methods}

The research uses methods of content analysis, structural and semantic analysis of educational texts presented in school textbooks of the Russian language for grades 4-7, as well as analysis of the process and results of the interpretation of educational texts of various semantic structures by students of grades 4-7 in Moscow schools (the study was conducted in 2018-2019 and 2019-2020 academic years).

\section{Results}

The result of the research is a description of the properties of educational texts in terms of their ability to activate the information activity of the student.

1. Structuring of educational texts is the process of presenting a certain fragment of scientific knowledge in a speech work. As a result, educational texts, on the one hand, implement the goal of science - "objective description, explanation and forecast of processes and phenomena of reality" [9, p. 108], on the other - the didactic task of presenting knowledge (fact, concept, regularity, method, idea) as a component of the content of training, a necessary component of the information field of the educational field, which the student considers as a comprehensible information space [10-13].

In the information activity of students with separate texts, there are two active stages: forecasting results and planning activities. Forecasting results and the nature of the information received replaces goal setting. This type of activity is defined by two components of the text: the title and the beginning, and the initial sentence. In educational texts, there are two types of titles: informational, indicating the conceptual field of the text, and motivational, 
designed with the help of popularisation tools. The research shows that the information title performs the controlling function to a greater extent.

Planning activities depends on the forecast of results: depending on what results the reader expects to get, they are ready to correlate the content of the text a. with the conceptual basis of a particular section of the subject, b. with the factual field of the topic, c. with their own cognitive experience. The organisation of receiving information is usually set by the teacher. Activation of activities at this stage is provided by the use of text dialogistic tools.

2. The integrity of information activity is observed when students can work with a content-thematic complex of texts-provided that they represent different types of actualisation of the value attitude to knowledge. The emphasis may be placed on the value of knowledge a. for society, b. for the author of the text, c. for the reader. In the first case (an impersonal type of actualisation of the value relation to knowledge), the student who gets acquainted with the text perceives the information distantly, as a certain unconditionally significant, but impersonal meaning. If the text presents knowledge as significant for the author (an authorised type of updating of the value attitude to knowledge), the reader enters into a dialogue with the author, realises the progress of obtaining knowledge, and finds answers to the questions posed by the author in the text. The emphasis on the significance of knowledge for the reader (a personal type of actualisation of the value attitude to knowledge) encourages the student to, first of all, relate knowledge to their own cognitive experience.

3. Each of the types of actualisation of the value attitude to knowledge is manifested in the interpretation of educational texts [14-17], transmitting their content in the information stream. The result of interpretation is a. description of facts from the subject area as selfsufficient knowledge (the objectivity of knowledge that is valuable for society as a whole is realised), b.description of facts from the subject area as the information received from the author of the text (the dialogistic of scientific and educational communication is realised), c. description of facts from the subject area based on the appeal to personal experience (the acceptance of knowledge as a fact of personal experience is implemented).

\section{Discussion}

The obtained results lead to the fact that the information activities of students are supported by a certain structure of academic texts: the availability of information title, introduction, tools of the axiological field of text, media work, organisation of interaction of text with the reader. It is known that the experience of information activity of a student as a reader of an educational text is enriched and developed only if the speech product provides evidence of the connections of the represented content with other components of the information space already mastered by the student $[7,18]$. Moreover, the attitude to knowledge as an objective phenomenon that does not depend on personal attitude is the final point of perception of scientific information. It is possible to predict the result of working with information, plan and organise the receipt of information, as well as to be aware of one's own information experience only through personal acceptance of each action [19-21]. Therefore, the full cycle of information activity of the student is provided by the presence in it of all three types of actualisation of the value attitude to knowledge. This implies saturation of the information space of the subject with educational texts of different types. However, there is a problem of thematic selection of texts for textbooks, their structural and semantic correlation becomes important, the possibility of embodying the content of several texts in single speech work, for example, in a student's message on the subject with elements of popularisation.

\section{Conclusion}


Consideration of an educational text as a didactic unit that provides the formation of the student's information activity experience requires attention to its components. They provide the forecast of performance, its planning, organisation, and control. Such components include the informational title, the beginning of the text, as well as axiologically significant structural and semantic components. The study showed that individual texts activate only two stages of information activity: forecasting results and planning. Holistic information activities can be organised when working with a set of texts united by updating the value attitude to knowledge.

The data obtained allow us to predict the results of working with an educational text as a source of information can be used in the creation of educational kits, the formation of school reference books, and the development of scenarios for training sessions.

\section{References}

1. Ya.A. Mick, Optimization of the complexity of the educational text: in help to authors and editors (Education, Moscow, 1981)

2. E.A. Kopylova, Educational dialogue as a factor in the formation of meaning in the process of teaching older students: diss. ... cand. ped Sciences (Tyumen, 2011)

3. E. Cer, SAGE Open 9(2), 1-17 (2019)

4. K.N. Haug, P.D. Klein, Reading \& Writing Quarterly 34(1), 47-62 (2018)

5. N. Mercer, K. Littleton. Dialogue and the Development of Children's Thinking (Routledge, London, 2017)

6. M. Spencer, A.F. Gilmour, A.C. Miller, A.M. Emerson, Reading and writing 32, 603637 (2019)

7. J. Van de Pol, S. Brindley, R. Higham, Educational Studies 43(5), 497-515 (2017)

8. R. Wijekumar, S. Graham, K.R. Harris, P-W. Lei, Reading and writing 32, 1431-1457 (2019)

9. N.D. Desiajeva, S.A. Arefieva, Stylistics of the modern Russian language: textbook for students (Academy, Moscow, 2008)

10. K. Beker, P. Broek, D. van den, Jolles, Reading and Writing 32, 663-687 (2019)

11. K. Berendes, S. Vajjala, D. Meurers, Journal of Educational Psychology 110(4), 518543 (2018)

12. M. W. Rodrigues, S. Isotani, L.E. Zárate, Telematics and Informatics 35(6), 1701-1717 (2018)

13. L. Salmerón, A. García, E. Vidal-Abarca, Learning and Individual Differences 61, 3139 (2018)

14. S. Brindley, M. Juzwik, A. Whitehurst, L1 Educational Studies in Language and Literature 16, 1-10 (2016)

15. G.C. Magulod Jr., SAGE Open 8, 1-11 (2018)

16. Y.J. Dori, International Journal of Science Education 40, 1198-1220 (2018)

17. M. Hebert, J.J. Bohaty, J.R. Nelson, J.V. Roehling, Reading and Writing 31, 2165-2190 (2018)

18. E.W. Brante, H.I. Stromso, Educational Psychology Review 30, 733-799 (2018)

19. M. Koster, R. Bouwer, Journal of Writing Research, 10(2) 189-224 (2018)

20. A. List, P.A. Alexander, Educational Psychologis 54(1), 20-39 (2019)

21. A. Masrai, SAGE Open 9(2), 1-13 (2019). 